\title{
NUMERICAL INVESTIGATION OF THE UNDRAINED COMPRESSION AND PULL-OUT CAPACITY OF SUCTION FOUNDATIONS IN CLAY
}

\author{
Jiaqing Du ${ }^{a}$ \\ Shouji $\mathrm{Du}^{\mathrm{a}}$ \\ Shuilong Shen ${ }^{\mathrm{a}}$ \\ Zhenyu Yin ${ }^{\mathrm{a}, \mathrm{b}}$ \\ ${ }^{a}$ Department of Civil Engineering and State Key Laboratory of Ocean Engineering, Shanghai Jiao \\ Tong University, Shanghai 200240, China

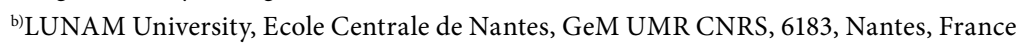

\begin{abstract}
This paper presents the results of three-dimensional finite difference analysis of suction foundations in uniform and non-uniform clays under undrained conditions. The Tresca criterion was used to simulate the stress-strain response. The bearing capacity of the foundations was investigated, with the degree of nonhomogeneity $(\mathrm{kD} / \mathrm{sum})$ of soil varying from 0 to 5, and the embedment depth being up to four times the foundation diameter. The end bearing capacity factor in compression and the reverse bearing capacity factor in tension were both calculated and were compared with each other under different foundation displacements. Numerical results showed that the ultimate bearing capacity factor can have the same value in cases of both compression and tension. The recommended ultimate bearing capacity factor is determined on the basis of the embedment ratio and displacement magnitude, and the displacement is not more than $30 \%$ of the foundation diameter. Finally, two equations are proposed to evaluate both the bearing capacity factor and the effective depth factor.
\end{abstract}

Keywords: bearing capacity factor, displacement, compression, tension, depth factor

\section{INTRODUCTION}

The suction foundation is a large diameter cylinder, which is open ended at the bottom and closed at the top. Suction foundations are so called because they are installed by pumping water out of the cylinder in order to generate a lower pressure or "suction" in its interior than that outside the cylinder after having settled under its self-weight. The difference between the hydrostatic water pressure outside the cylinder and the reduced water pressure inside creates a differential pressure that acts as an additional penetration force. Once installed, the foundation acts like a short rigid pile and is capable of resisting both lateral and axial loads [1]. With the advantages of easy installation, short installation time, high degree of reliability and low cost, suction foundations have been used extensively in offshore facilities, such as foundations of jacket structures, current and wind turbines, subsea systems seabed protection structures and as anchors for floating production storage and offloading (FPSO) units, tension leg platforms (TLP), and SPAR platforms [2].

Suction foundations have a larger diameter and longer side wall compared to traditional pile foundations and shallow foundations. After installation, the interior is sealed off and the pullout loading creates a passive suction, which mobilizes the end bearing resistance of the soil at the skirt tip. Considering passive suction, it is assumed that the suction foundation has the same bearing capacity in uplift and compression. Currently the ultimate uplift capacity of a suction foundation is calculated by side friction and the reverse bearing capacity: 


$$
q_{u l t}=N_{c} s_{u, t i p}+4 \frac{L}{D} \alpha s_{u, a v}+q_{p l u g}-q_{0}
$$

where $\mathrm{q}_{\mathrm{ult}}$ is the ultimate bearing stress on the foundation. $\alpha$ is the adhesion factor, usually taken as 0.5 to 1.0 . $\mathrm{L}$ is the embedment depth and $\mathrm{D}$ is the foundation diameter. $\mathrm{N}_{c}$ is the bearing capacity factor of the circle footing and varies with the embedment ratio. The value of the surface of the foundation resting on cohesive and frictionless soil is 6.05 [3]. $s_{\text {utip }}$ is the undrained shear strength of the soil at the foundation tip level, $s_{u, a v}$ is the average undrained shear strength over the penetration depth. $\mathrm{q}_{\text {plug }}$ is the self-weight of soil plug and $\mathrm{q}_{0}$ is the surcharge at the foundation base level.

There are many studies referring to the bearing capacity factor in compression and its relationship to the shear strength $[4,5]$. Hu et al. investigated the bearing response of skirted foundations on uniform and nonhomogeneous soil using a displacement finite element analysis approach, in which the embedment ratio of the skirted foundation varied from 0 to 0.5 [4]. Houlsby and Martin considered a conical footing embedded in clay using the stress field method [5]. A finite element limit analysis method was employed by Salgado et al. to investigate the upper- and lower-bound solutions of circular foundations embedded in clay [6]. Edwards et al. investigated the bearing capacity factor of embedded foundations using a displacement finite element analysis approach with the embedment ratio of the foundation varying from 0 to 4 [7]. Generally, a suction foundation needs a large displacement in compression to achieve ultimate capacity [4]. Hu et al. reported that the penetration displacement of a deeply embedded foundation may be at least $4 \mathrm{D}$ to reach a limit load. However, a large displacement is not necessary to achieve ultimate pull-out capacity in an uplift loading case. Furthermore, the difference in displacement magnitude between compression and tension cases may have a great effect on bearing capacity factors. Finn and Byne proposed a reverse bearing mechanism under uplift in undrained conditions, and recommended that the reverse capacity factor for the uplift loading case is taken as the same value as the compression case [8]. There are a number of centrifuge tests for investigating the difference of skirted foundations $(\mathrm{L} / \mathrm{D} \leq 1)$ under the condition of compression and uplift. Watson et al. and Mana et al. reported the same magnitudes of undrained uplift capacity and compression capacity, while Acosta-Martinez et al. observed 30\% reduction in uplift capacity compared to compression capacity [9-11]. The magnitude of passive suction is the key factor to mobilize the reverse capacity. However, the magnitudes of loading rate and preload are the uncertain factors to affect the mobilized uplift capacity. Chatterjee et al. investigated the undrained compression and uplift capacity using large-deformation numerical methods and concluded that the two cases have the same bearing capacity [12]. However, both the centrifuge tests and numerical modeling were aimed at the smaller embedment radio, the bearing factor increased with the embedment ratio and the larger displacement is needed to mobilize the capacity for longer foundation. Therefore, a range of embedment ratios were investigated to establish the bearing factors and displacement magnitudes in the cases of undrained compression and uplift.

The objective of this paper is to investigate the difference in the bearing capacity factors of suction foundations in cases of both compression and tension. These factors include the embedment depth, the degree of nonhomogeneity, and the foundation displacement. The results will be useful for the design of suction foundations and have potential applications in offshore marine engineering.

\section{NUMERICAL MODELLING}

This study focuses on the comparison of the bearing factors in the cases of undrained compression and uplift. In the numerical modeling, the suction foundations were simplified as solid foundations and the reasons are listed as followed: (1) both the failure faces of suction foundations in undrained compression and uplift cases are under the base of foundation, this is similar with solid foundation;(2) the bearing capacity factor is calculated based on the undrained shear capacity of soil below the foundation; (3) both the soil and foundation were set weightless to make the effects of soil plug and surcharge vanished. Small-strain analysis of embedded suction caisson foundations was conducted using the FLAC3D software. In order to be consistent with existing design methods and to compare with the results from other studies, the soil was modelled as a linear elastic-perfectly plastic model based on the Tresca failure criterion.

\section{HOMOGENEOUS CLAY}

A constant undrained shear strength, $\mathrm{s}_{\mathrm{u}}$, equal to $5 \mathrm{kPa}$ and a Young's modulus, $\mathrm{E}_{\mathrm{u}}$, of $400 \times \mathrm{s}_{\mathrm{u}}$, were assigned to the soil. A Poisson's ratio of 0.495 was applied to simulate the constant volume response of clay under undrained conditions. The suction caisson foundation had a Young's modulus of $\mathrm{E}=\mathrm{E}_{\mathrm{u}} \times 106$, and was considered to be rigid. The interfaces in the foundation base and side were assumed to be rough and smooth respectively. The rough case was to restrain the horizontal movement of nodes. In the uplift case, any detachment between the foundation base and soil was prevented.

Loading was applied using the displacement-controlled method as it is more suitable than the stress-controlled method to obtain the failure load. All analysis was conducted by applying uniform vertical displacements and zero horizontal displacements to the nodes of the foundation until the failure state was reached. The ultimate load on the footing was then calculated as the sum of the vertical reaction forces on the nodes. This load is equal to the net bearing force, whose value is equivalent to $\mathrm{N}_{c} \mathrm{~s}_{\mathrm{u}} \mathrm{A}$. The effect of side friction and surcharge were not included in the load, since the side interface was assumed to be smooth and the soil was weightless. The calculated area A should contain half the zone width adjacent to the footing edge (since forces are exerted on the footing by this zone, it is assumed that the forces are divided equally between the left and right grid points).

Fig. 1 shows a typical mesh used in the present study. 
Owing to the symmetry in geometry and loading conditions, only half of the domain was discretised. $\mathrm{L}$ is the embedded length and $\mathrm{D}$ is the diameter of the foundation. The $\mathrm{L} / \mathrm{D}$ ratio had the values of 0 (surface foundation), $0.5,1,2,3$, and 4 . Displacements at the lower boundary were fully fixed in the $\mathrm{x}, \mathrm{y}$, and $\mathrm{z}$ directions. Normal displacements at the lateral boundaries were constrained. The size of the soil elements increased gradually from the foundation to the domain boundary. The length from the foundation to the domain boundary was set at 5.5D (including $1 \mathrm{D}$ finer areas under foundation) to minimize the boundary effects. Initially, in order to establish the accuracy of the finite difference analysis, the grid was adjusted to obtain a suitable bearing capacity factor by comparing with the known solutions. A factor $\mathrm{N}_{c}$ of 6.10 was obtained for the suction foundation, which is $0.8 \%$ in error compared with the solution obtained by Eason and Shield (1960) with a factor of 6.05.

\section{NONHOMOGENEOUS CLAY}

In a normally consolidated or a lightly overconsolidated marine clay, suction caissons need to penetrate deeper due to the soft clay in the shallow seabed being unable to provide sufficient strength. This is because for marine sediment, the shear strength increases with depth. The undrained shear strength, su may be idealised as approximately linearly with depth, which can be expressed as

$$
s_{u}=s_{u m}+k z
$$

where $\mathrm{s}_{\mathrm{um}}$ is the soil strength at the seabed (mud line); $\mathrm{k}$ is the strength gradient; and $\mathrm{z}$ is the soil depth (see Fig. 2). The dimensionless ratio $\mathrm{kD} / \mathrm{s}_{\mathrm{um}}$ is taken to quantify the degree of strength nonhomogeneity beneath the foundation. The value of $\mathrm{k}$ is typically found in the range of $0.6-3.0 \mathrm{kPa} / \mathrm{m}$ for clay materials [13]. Typically, the foundations have diameters (or widths), D, ranging from 3 to $10 \mathrm{~m}$ (but may be much larger for skirted foundations of gravity platforms), and the embedment ratio is not more than 6 . Five values of the dimensionless ratio, $\mathrm{kD} / \mathrm{s}_{\mathrm{um}}=1,2,3,4,5$; and the embedment ratio varying from 0 to 4 were examined in the studies described below.

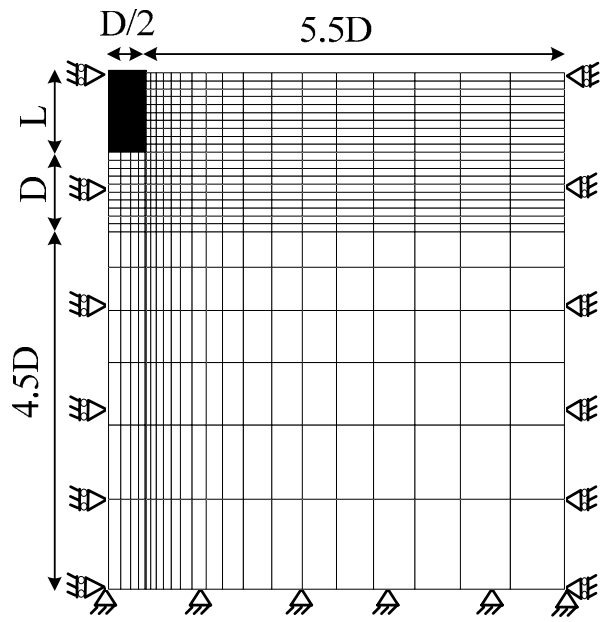

Fig. 1 Finite difference mesh in homogeneous clay

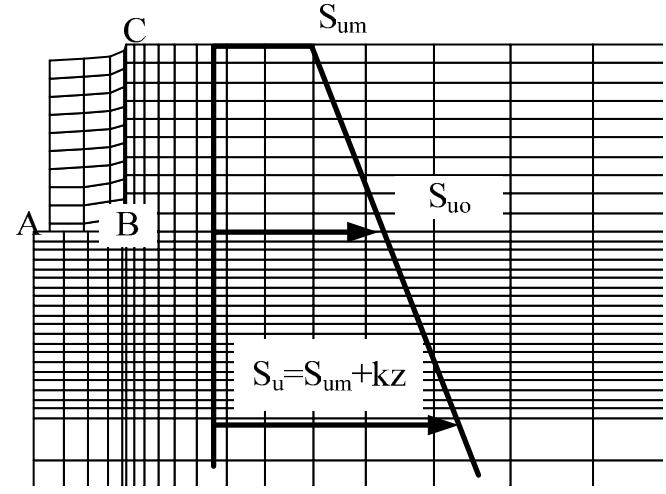

Fig. 2 Finite difference mesh in nonhomogeneous clay

\section{ANALYSIS RESULTS}

\section{HOMOGENEOUS CLAY}

Fig. 3 summarises the results from the suction foundation analysis in compression, and compares the solutions with those of Hu et al. (1999), Houlsby and Martin (2003), Salgado et al. (2004), Edwards et al. (2005) and Hansen (1970) [4-7,14]. The diagram shows the variation of $\mathrm{N}_{c}$ with embedment ratio $\mathrm{L} / \mathrm{D}$. The rough condition at the base of the footing and the uniform undrained shear strength condition in the soil are employed in the model. The finite difference analysis results for the smooth-sided footings are very close to the finite element analysis results of Edwards et al. (2005), and both fall within the range of the upper- and lower-bound solutions of Salgado et al. (2004). This confirms the accuracy of the finite difference analysis. The curves obtained from the finite element analysis of Hu et al. (1999) are above those of Hansen (1970) and below other studies (excluding the stress field method, Houlsby and Martin (2003)) for $L / D>1$.The reason for this may be that the $\mathrm{Nc}$ value (Hu et al. 1999) was obtained when the foundation displacement was equal to $0.3 \mathrm{D}$, and the displacement magnitude cannot reach the limit load for $\mathrm{L} / \mathrm{D}>1$. However, it is possible to achieve limit load at $0.3 \mathrm{D}$ displacement for $\mathrm{L} /$ $\mathrm{D} \leq 1$. Therefore, the results from Hu et al. (1999) are similar to other finite element and finite difference analyses for $\mathrm{L} / \mathrm{D} \leq 1$.

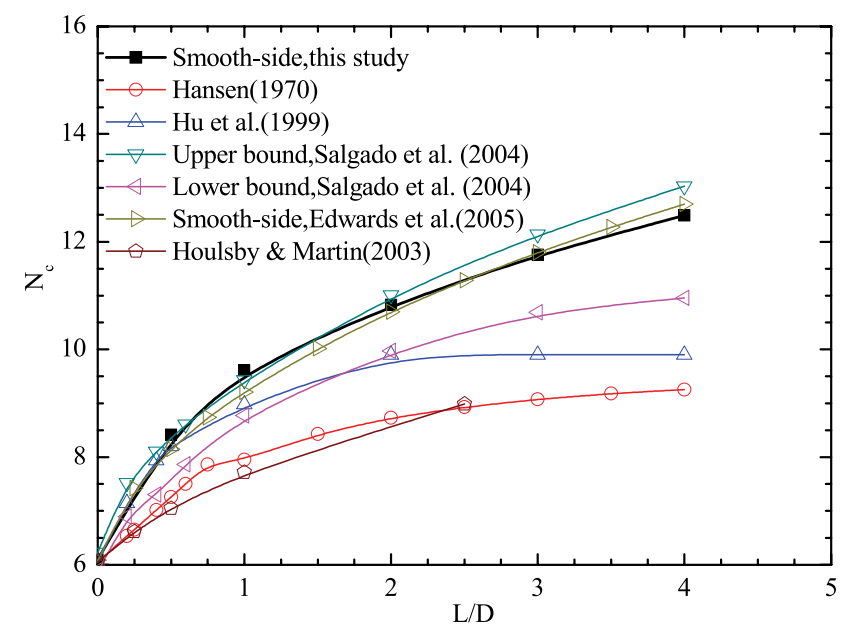

Fig. 3 Comparison of vertical bearing capacities 
Fig. 4 presents the normalised vertical load-displacement curves in compression and tension. In the compression case, the ultimate bearing capacity was mobilised at different displacement magnitudes with various embedment ratios. The limit displacements $0.05 \mathrm{D}, 0.3 \mathrm{D}, 0.5 \mathrm{D}, 2 \mathrm{D}, 3 \mathrm{D}$, and $3 \mathrm{D}$ correspond to embedment ratios of $0,0.5,1,2,3$, and $4.2 \mathrm{D}$ displacement is required to achieve the limit load for $\mathrm{L} / \mathrm{D}>1$. In the tension case, the limit displacement magnitude is identical to that for the compression case for $\mathrm{L} / \mathrm{D} \leq 1$; the curves overlap and the bearing capacity factors Nc converge at 10.3, while the displacement reaches $0.8 \mathrm{D}$ for $\mathrm{L} / \mathrm{D}>1$.
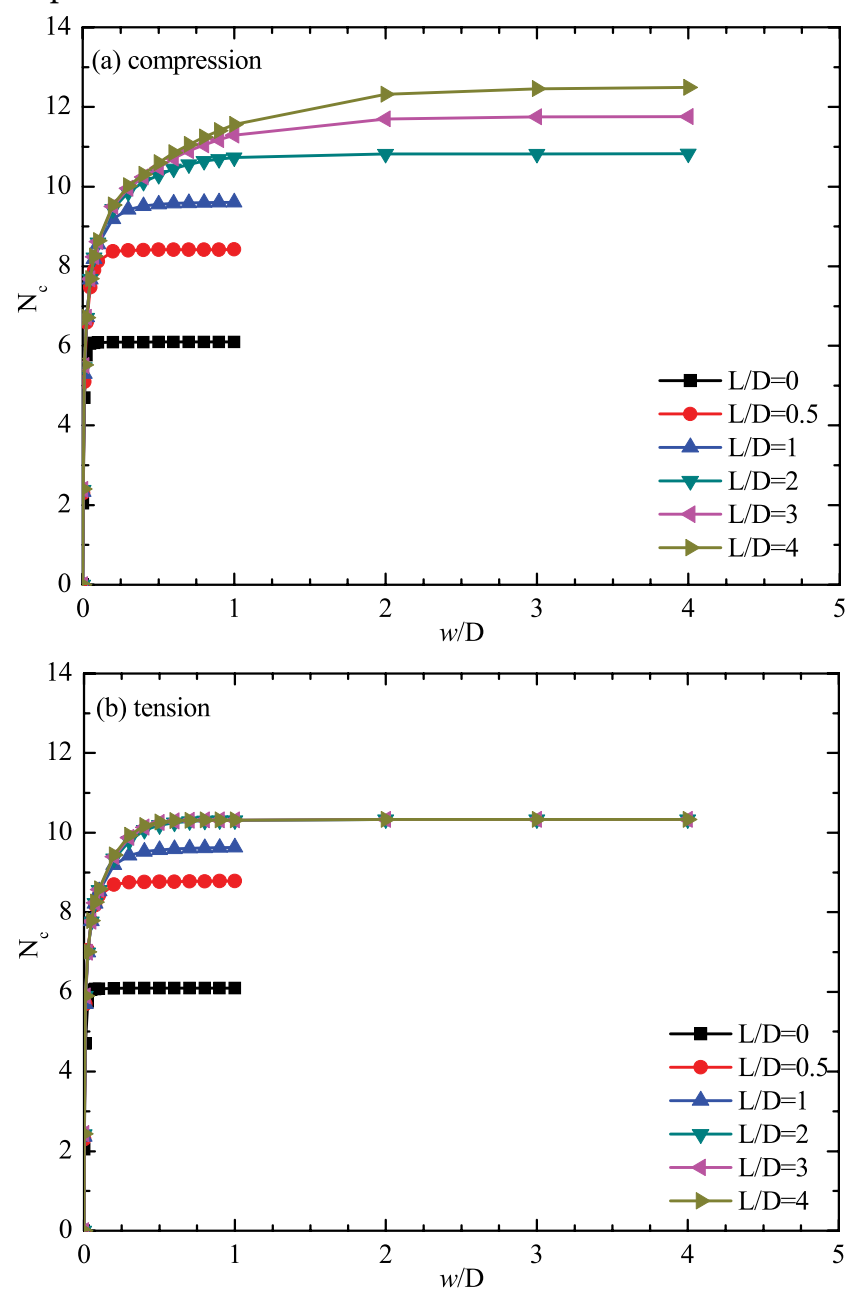

Fig. 4 Normalised load-displacement curve according to L/D ratios

In engineering practice, a large displacement would affect the normal use of a foundation or super structure so that a smaller displacement would usually be taken as the ultimate displacement of the foundation. Fig. 5 presented the statistic datas from a range of centrifuge tests $[10,11,15,16]$ and $1 \mathrm{~g}$ tests [17-20]. The ultimate displacements are not more than $0.1 \mathrm{D}$ and $0.2 \mathrm{D}$ when the embedment ratios less than 1 and 2 . Furthermore, the ultimate displacements are merely around $0.3 \mathrm{D}$ even for the embedment ratios exceed 4 . Therefore, the displacements of $0.1 \mathrm{D}, 0.2 \mathrm{D}$, and $0.3 \mathrm{D}$ were selected to compare with the limit displacement in numerical modeling. Figure 6 shows the vertical capacity of the foundation according to the $\mathrm{L} / \mathrm{D}$ ratios. The diagram presents a comparison of bearing capacity factors at $0.1 \mathrm{D}, 0.2 \mathrm{D}, 0.3 \mathrm{D}$, and limit displacement (corresponding to the limit load) in compression and tension. As shown in Fig. 6, the bearing factor curves in compression and tension show very little difference at $0.1 \mathrm{D}, 0.2 \mathrm{D}$, and $0.3 \mathrm{D}$ displacement, however, they show a great difference at limit displacement. Therefore, the same bearing capacity factor can be taken in compression and tension design when the displacement is relatively small. Comparing the results shown in Fig. 3 and Fig. 6, it can be seen that the curve derived from Hansen's results is most close to the results of $0.1 \mathrm{D}$ and $0.2 \mathrm{D}$ displacement, which suggests that Hansen's formula is still useful in engineering practice.
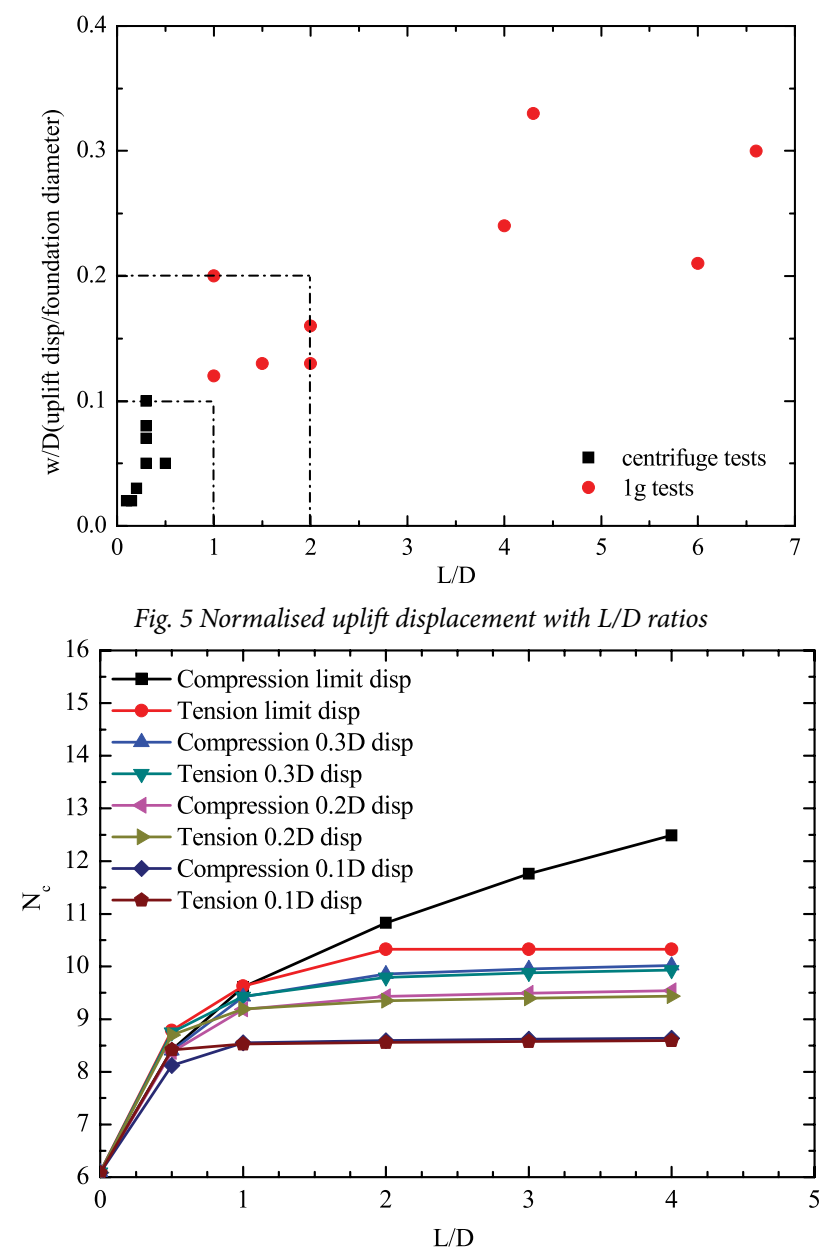

Fig. 6 Vertical bearing capacity according to $L / D$ ratios

\section{NONHOMOGENEOUS CLAY}

Fig. 7 presents the bearing capacity factors from finite difference analysis according to $\mathrm{L} / \mathrm{D}$ ratios in heterogeneous soils. There are a few comparisons which can be made with published work, where the dimensionless ratio $\mathrm{kD} / \mathrm{s}_{\mathrm{um}}$ varies from 1 to 5 . Hu et al. (1999) has investigated the bearing capacity factors with the embedment ratio varying from 0 to 0.5 using the upper boundary method and finite element analysis. As shown in Fig. 6, the finite difference solution is close to the finite element result and the plots are both below the upper-boundary curve. In contrast, the curve from the 

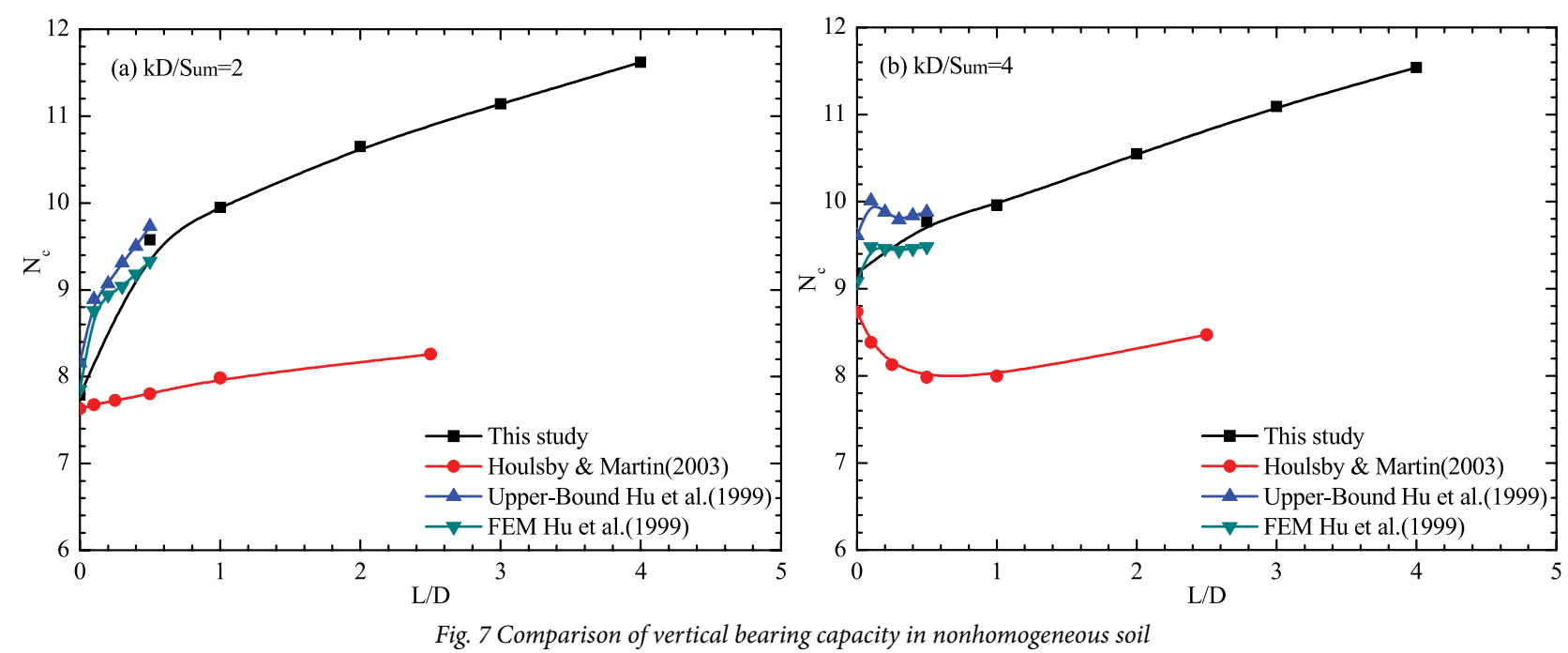

stress field method proposed by Houlsby and Martin (2003) shows significant differences from the plots derived from the finite difference analysis. The stress field solutions predict much smaller bearing capacity factors than the current finite difference analysis. From the comparison of published solutions for homogeneous soil (see Fig. 3), it can be seen that the stress field solutions are even smaller than the lower-bound solutions. Thus, the results from Houlsby and Martin (2003) can be taken as lower-bound solutions in nonhomogeneous soil.

Fig. 8 and 9 show the curves of bearing capacity factors with embedment ratio at different footing displacements in compression and in tension respectively. In the compression case, the curves are indistinguishable up to $\mathrm{L} / \mathrm{D}=0.5$, after which the $0.1 \mathrm{D}$ displacement curve begins to deviate from others. The $0.2 \mathrm{D}$ displacement curve does not separate from the other curves until $\mathrm{L} / \mathrm{D}=1.0$. Therefore, the resistance corresponding to $0.1 \mathrm{D}$ displacement and to $0.2 \mathrm{D}$ displacement can be taken as the limit load for $\mathrm{L} / \mathrm{D}<1$ and $1 \leq \mathrm{L} / \mathrm{D}<2$ respectively. The curves in the tension condition have a similar tendency to the compression case for $\mathrm{L} / \mathrm{D} \leq 1$. When the embedment ratio reaches 2 , the $0.3 \mathrm{D}$ displacement curve also diverges from the limit displacement curve in the compression case. In contrast, the $0.3 \mathrm{D}$ displacement curve differs little from the

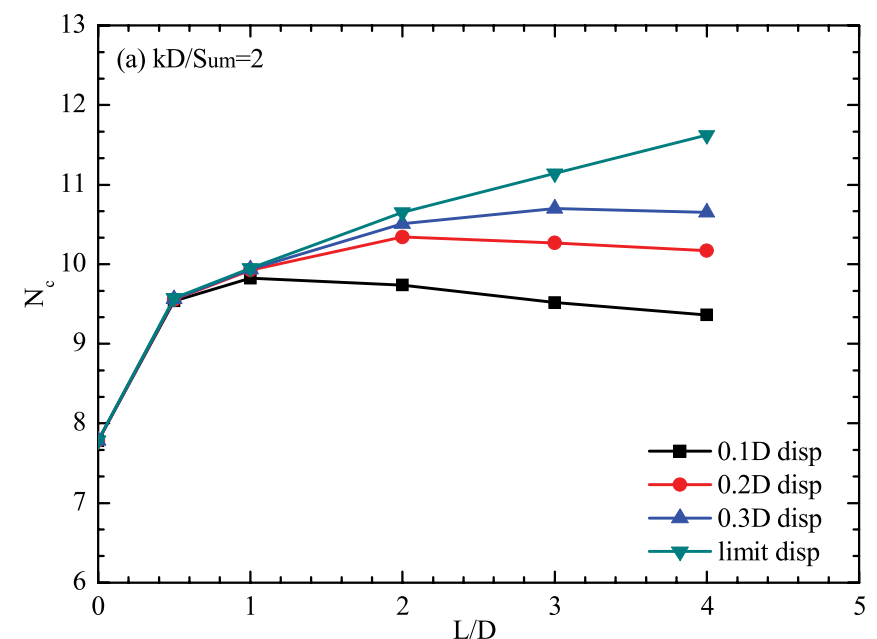

limit displacement curve in the tension case. In practice, the resistance corresponding to $0.3 \mathrm{D}$ displacement can be taken as the limit load for $\mathrm{L} / \mathrm{D} \geq 2$ in both the compression and tension cases.

Fig. 10 and 11 show the curves of bearing capacity factors with the degree of nonhomogeneity at different footing displacements, in compression and tension, respectively. In the case of compression, the bearing capacity factor increases linearly with the degree of heterogeneity for the surface foundation. The growth of bearing capacity factor is slow with the increasing heterogeneous degree for embedded foundations, especially in the range where the nonhomogeneous degree varies from 1 to 5 . The increment is largely in the transition zone from uniform to nonhomogeneous soil (where $\mathrm{kD} / \mathrm{s}$ varies from 0 to 1 ), after which the curves become flat. In the limit displacement condition, bearing capacity factors in the uniform soil are even higher than the factors in nonhomogeneous soil for $\mathrm{L} / \mathrm{D} \geq 2$. In the case of tension, the trend of the bearing capacity factor curve was similar to that in compression to a great extent. Comparison of the curves show that when the footing displacement reaches the limit values, the values of $\mathrm{N}_{c}$ change little with the increase of degree of nonhomogeneity and are almost equal to 10.3 for $\mathrm{L} / \mathrm{D} \geq 2$.

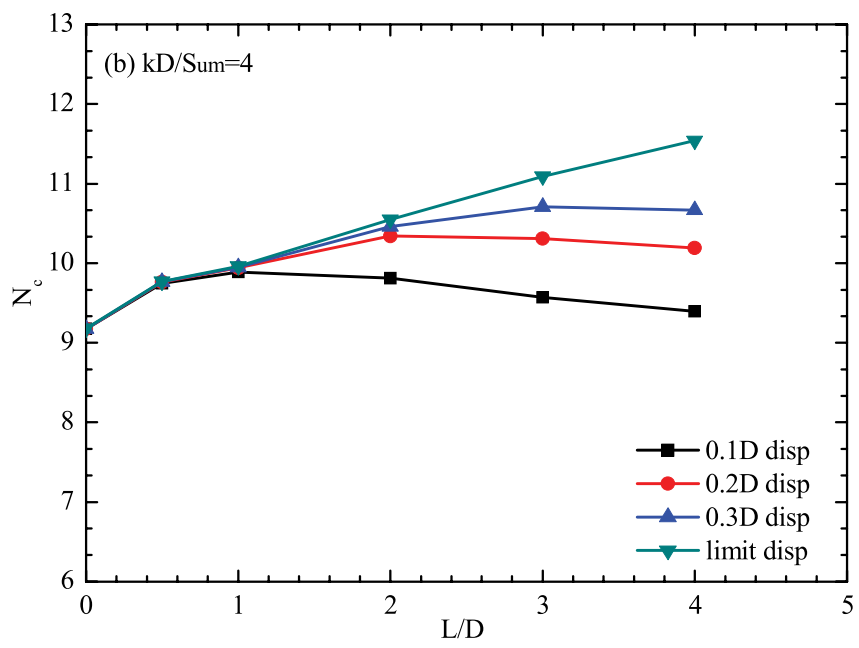

Fig. 8 Bearing capacity of suction foundation with smooth side in compression 

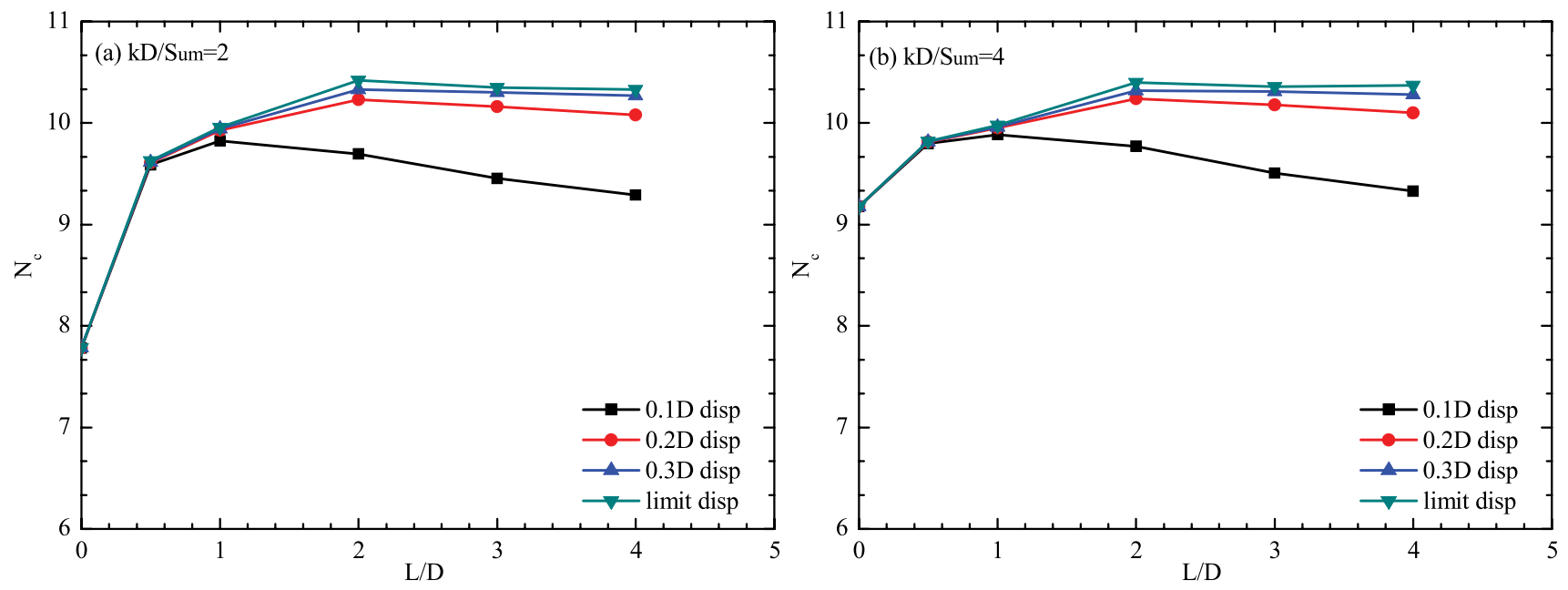

Fig. 9 Bearing capacity of suction foundation with smooth side in tension

\section{DISCUSSION}

Fig. 12 presents the recommended bearing capacity corresponding to the appropriate displacement with embedment ratio. The displacement $0.1 \mathrm{D}, 0.2 \mathrm{D}$, and $0.3 \mathrm{D}$ is taken for $\mathrm{L} / \mathrm{D}<1,1 \leq \mathrm{L} / \mathrm{D}<2$, and $\mathrm{L} / \mathrm{D} \geq 2$, respectively. Since the bearing capacity values and tendency are similar in the compression and tension case, the same value can be taken in design. The undrained shear strength of soil have a significantly effect on the bearing factor also. There are some experimental methods to measure the undrained strength. Triaxial compression, triaxial extension and direct shear test were used to measure the undrained shear strength regularly,
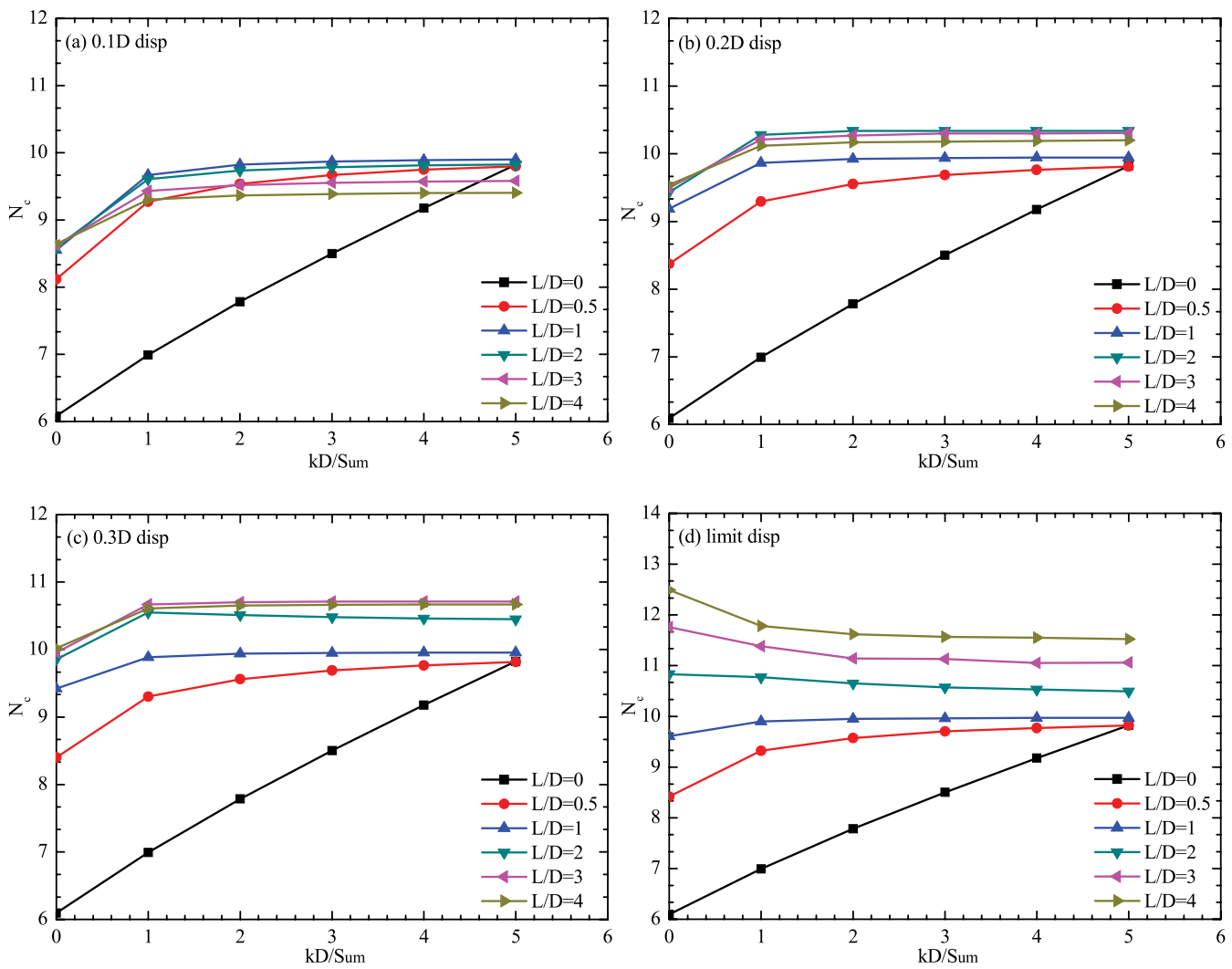

Fig. 10 Bearing capacity of suction foundation with a degree of inhomogeneity in compression and some in-situ methods such as Vane, CPT and T-bar were employed also. However, there are some differences among the tests results. Regularly, triaxial compression has a higher value, triaxial extension has a lower value and simple shear test has a mean value. The results from vane test are higher than other tests [21]. Randolph and Hose (2002) reported that the averaged shear strength obtained from triaxial compression, triaxial extension and simple shear tests have 30\% and 50\% reduction compared to triaxial extension strength and triaxial compression strength respectively [22]. In order to minimize the influences of anisotropy, the averaged shear strength was suggested to represent the undrained shear strength in calculation of bearing factors. Several researchers

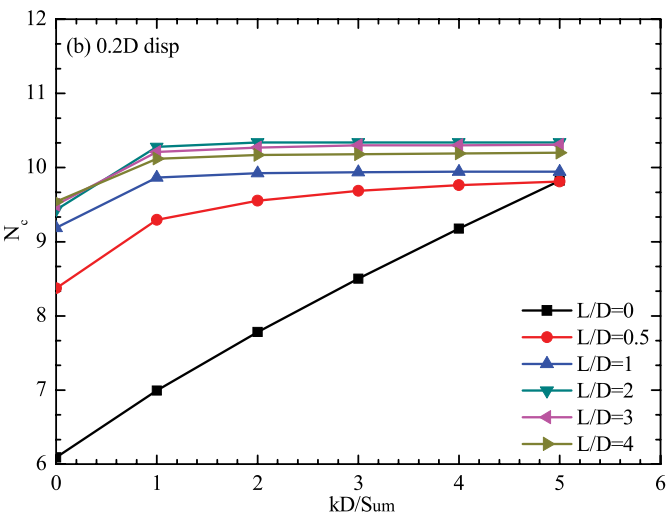



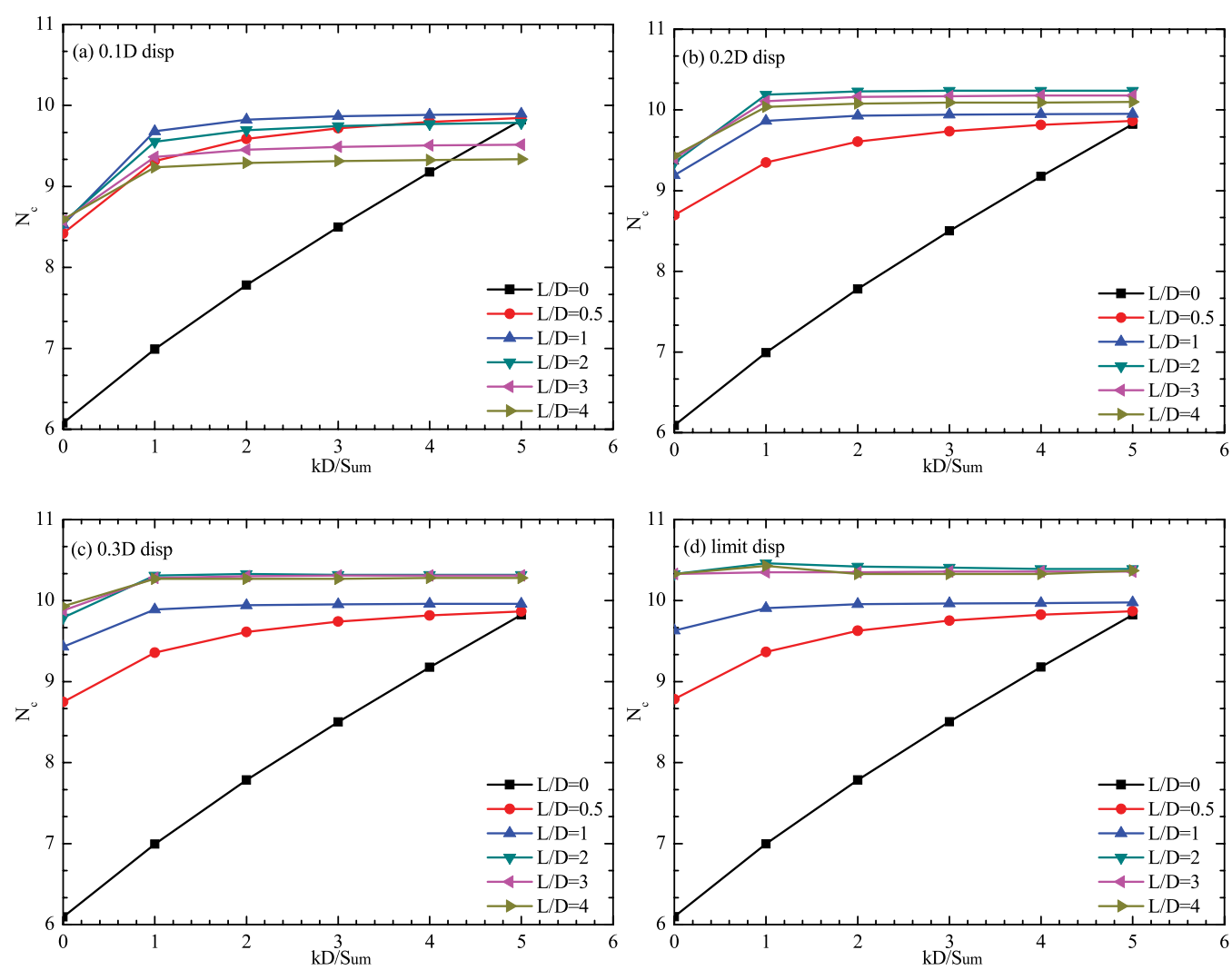

Fig. 11 Bearing capacity of suction foundation with a degree of inhomogeneity in tension

have suggested that $\mathrm{s}_{\mathrm{u}}$ can be taken as the value at depth $\mathrm{D} / 3$, D/4 or D/10 [23-25] below the skirt tip. Fig. 13 presents the bearing capacity factor results of $s_{u}$ at depth $D / 10$ below the base of foundation. Regardless of the compression or tension case, the curves for nonhomogeneous soil almost overlap. Comparing with the curves from Fig. 12, the bearing capacity curves for non-uniform clay are much closer to those for uniform clays. Therefore, the bearing capacity value in uniform clay can be used as a substitute for the value in non-uniform clay for the approximation, and it is conservative in design. Fig. 4 shows the back-calculated $\mathrm{N}_{\mathrm{c}}$ according to the $\mathrm{L} / \mathrm{D}$ ratios, and Eq. (3) fits with the data points very well. In addition, the depth factor $\mathrm{dc}$ is often used to describe the relationship between the bearing capacity factor and the embedment ratio. Eq. (4) was suggested to evaluate depth factor $d_{c}$, and the value of $\mathrm{d}_{\mathrm{c}}$ is not more than 1.7.

$$
\begin{gathered}
N_{c}=6.08[1+0.45 \arctan (2 L / \mathrm{D})] \\
d_{c}=1+0.45 \arctan (2 L / \mathrm{D})
\end{gathered}
$$

Fig. 15 indicates the comparison results of fitted curves of depth factor in this study with other studies [14,25-27].
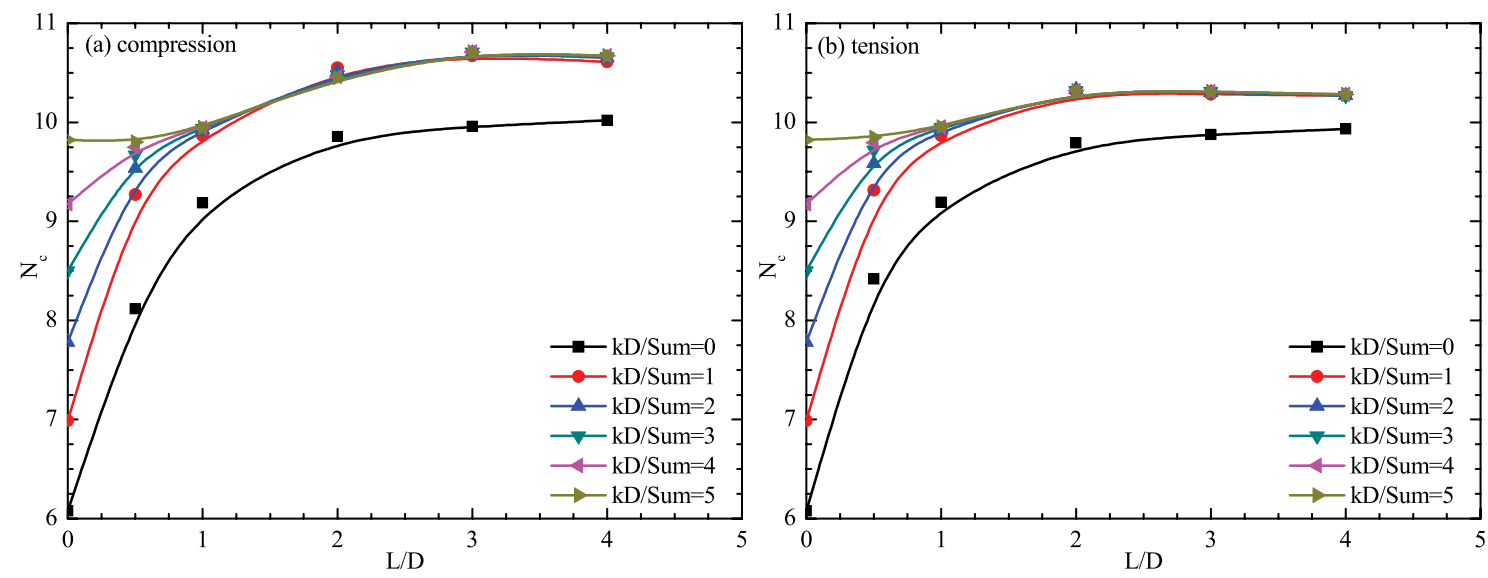

Fig. 12 Recommended bearing capacities with embedment ratios (su at the base of foundation) 

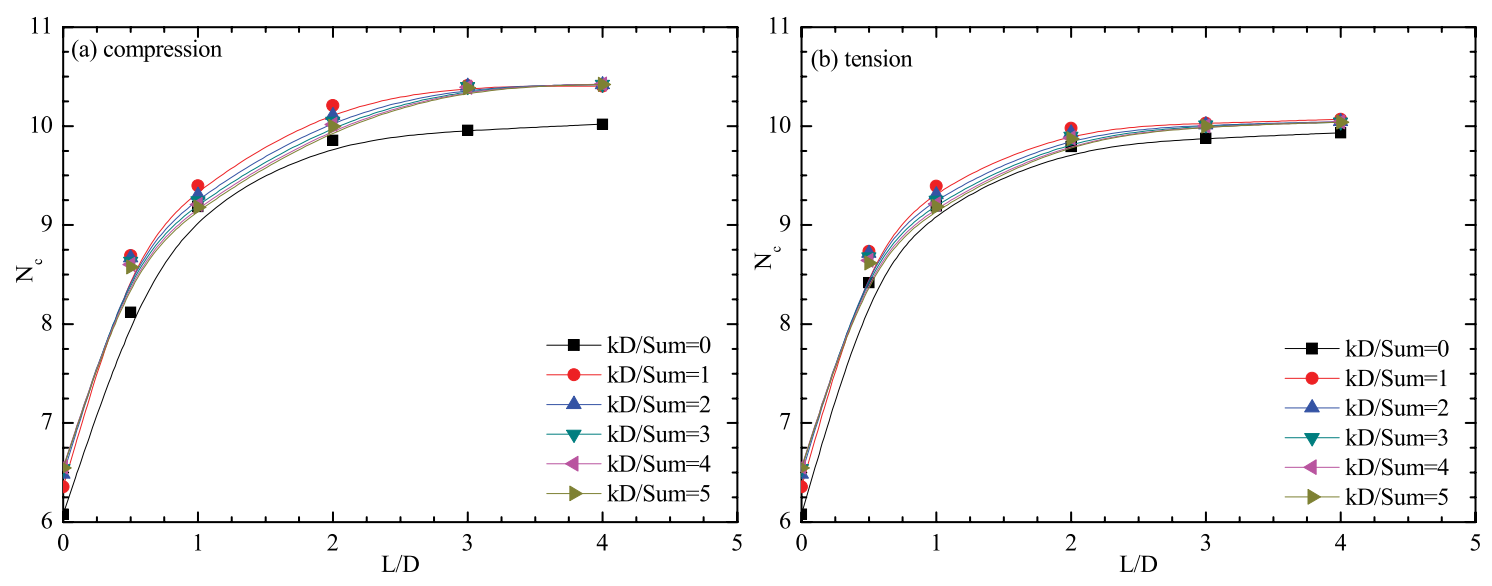

Fig. 13 Recommended bearing capacities with embedment ratios (su at the depth D/10 below the foundation)

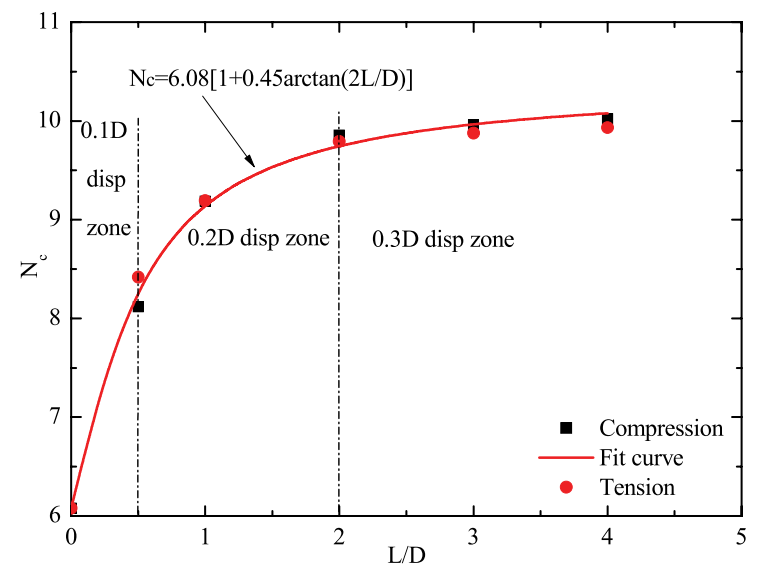

Fig. 14 Fitted curve using the results in uniform clay

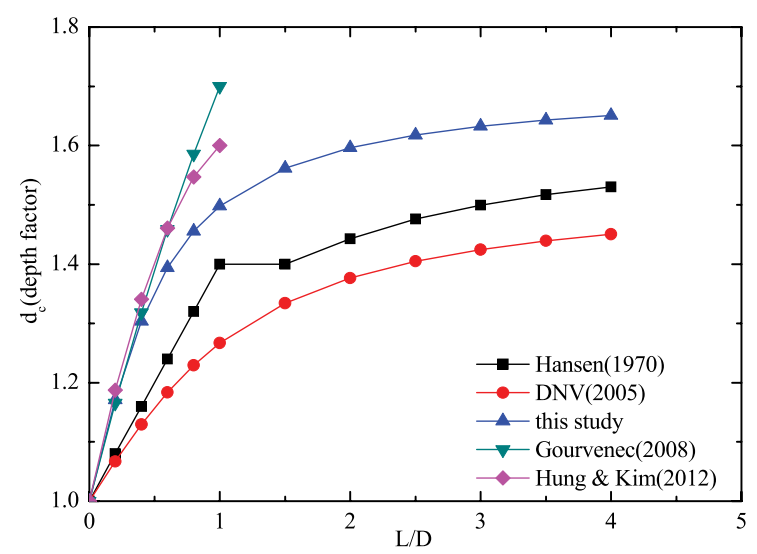

Fig. 15 Comparison of vertical depth factors

The results from finite element analyses proposed a quadratic relationship between ultimate vertical capacity and embedment ratio, for $\mathrm{L} / \mathrm{D} \leq 1$ [11,25]. Hansen (1970) suggested a liner relationship for $\mathrm{L} / \mathrm{D} \leq 1$ and an arctangent relationship for $\mathrm{L} / \mathrm{D}>1$ [14]. Over the range of embedment ratios $0 \leq \mathrm{L} / \mathrm{D} \leq 4$, the depth factors of this study and DNV can be described by the arctangent expression. The factors in this study are similar with Gourvenec and Hung's research in the section of $L / D<1$, but have higher values compared to Hansen's and DNV's in the section of $\mathrm{L} / \mathrm{D}>1$. The reason of the difference is that the larger displacement is allowed in the higher embedment ratios.

\section{CONCLUSION}

This paper presents the comparison results of a finite difference investigation on the undrained bearing capacity of suction foundations under situations of both compression and tension in uniform and non-uniform clay. The following conclusions were drawn:

1. There is a small difference in ultimate bearing capacity between compression and tension loading for the case that the embedment depth is less than two diameters. When the embedment ratio increases from 2 to 4 , the ultimate capacity in compression increases by sixteen percent, but the capacity in tension almost remains at the same level.

2. The bearing capacity factors change significantly when the clay varies from homogeneity to heterogeneity. There is a small change when the nonhomogeneous degree varies from 1 to 5 . The bearing capacity factors increases with the growth of nonhomogeneous degree.

3. In practical engineering, the values of bearing capacity factors corresponding to the displacement of less than $30 \%$ diameters $(0.3 \mathrm{D})$ can be taken as the ultimate bearing capacity factors, for both compression and tension cases. The bearing capacity factors in nonuniform clay are approximate to the factors in uniform clay when the su was selected at depth $\mathrm{D} / 10$ below the skirt tip.

4. Considering the embedment ratio, a new equation for calculating depth factor is proposed.

\section{ACKNOWLEDGEMENTS}

The research work described herein was funded by the National Nature Science Foundation of China (NSFC) (Grant 
No. 41372283), and the Innovative Research Project of Shanghai Municipal Education Commission (Grant No. 13ZZ021). These financial supports are gratefully acknowledged.

\section{REFERENCES}

1. Andersen, K.H., Murff, J.D., Randolph, M.F., Clukey, E.C., Erbrich,C.T., Jostad, H.P., et al.. Suction anchors for deepwater applications. In: Proceedings of the 1st International Symposium on Frontiers in Offshore Geotechnics, ISFOG, Perth. pp. 3-30,2005.

2. Hossain, M. S. Lehane, B. M. Hu, Y. Gao, Y.. Soil flow mechanisms around and between stiffeners of caissons during installation in clay. Can. Geothch.J. 49(4), 442-459, 2012.

3. Eason, G. \& Shield. R. T.. The plastic indentation of a semi-infinite solid by a perfectly rough circular punch. J. Appl. Math. Phys. 11, No. 1, 33-43, 1960.

4. Hu, Y., Randolph, M. F., and Watson, P. G.. Bearing response of skirted foundation on nonhomogeneous soil. J. Geotech. Geoenviron. Engng., ASCE 125, No. 11, 924-935.

5. Houlsby, G. T. and Martin, C. M.. Undrained bearing capacity factors for conical footings on clay. Géotechnique 53, No. 5, 513-520, 2003.

6. Salgado, R., Lyamin, A. V., Sloan, S. W. \& Yu, H. S.. Two and three-dimensional bearing capacity of foundations in clay. Geotechnique 54, No. 5, 297-306, 2004.

7. Edwards, D.H., Zdravkovic, L., Potts, D. M.. Depth factors for undrained bearing capacity. Géotechnique 55, No. 10, 755-758, 2005.

8. Finn, W.D.L. and Byne, P.M.. The evaluation of the breakout force for a submerged ocean platform. Offshore Technology Conference, OTC 1604, Houston, pp351-365, 1972.

9. Watson, P. G., Randolph, M. F., and Bransby, M. F.. "Combined lateral and vertical loading of caisson foundations." Proc., Annual Offshore Technology Conf., Offshore Technology Conference, Houston, OTC 12195, 2005.

10. Mana, D. S. K., Gourvenec, S. M., and Randolph, M. F.. "Experimental investigation of reverse end bearing of offshore shallow foundations." Can. Geotech. J., 50(10), 1022-1033, 2013.

11. Acosta-Martinez, H.E., Gourvenec, S.M., and Randolph, M.F.. An experimental investigation of a shallow skirted foundation under compression and tension. Soils and Foundations, 48(2): 247-254, 2008.
12. Chatterjee, S., Randolph, M. F., and White, D. J.. "Large-deformation numerical modeling of short-term compression and uplift capacity of offshore shallow foundations." J. Geotech. Geoenviron.Eng.140(3) 04013021-1-9, 2014

13. Tani, K., Craig, W.H.. Bearing capacity of circular foundations on soft clay of strength increasing with depth. Soils and Foundations, 35(4), pp 21-35, 1995.

14. Brinch Hansen, J.. A revised and extended formula for bearing capacity, Bullentin NO.28. Danish Geotechnical Institute, 1970.

15. Acosta-Martinez, H.E., Gourvenec, S.M., and Randolph, M.F.. Effect of gapping on the transient and sustained uplift capacity of a shallow skirted foundation in clay. Soils and Foundations, 50(5): 725-735, 2010.

16. Gourvenec, S., Acosta-Martinez, H.E., Randolph, M.F.. Experimental study of uplift resistance of shallow skirted foundations in clay under transient and sustained concentric loading. Géotechnique 59, No. 6, 525-537, 2009.

17. Rao, S.N.,Ravi, R.,Prasad, B.S.. "Pullout behavior of suction anchors in soft marine clays." Marine georesources \& geotechnology,15(2),95-114,1997.

18. El-Gharbawy. S. L. The pullout capacity of suction caisson foundations. $\mathrm{PhD}$ thesis, The University of Texas at Austin,1998.

19. Villalobos, F. A.,Byrne, B. W.,Houlsby, G. T. Model testing of suction caissons in clay subjected to vertical loading. Applied Ocean Research,32(4):414-424, 2010.

20. Guo, Zhen,Wang, Li-Zhong,Yuan, Feng. Set-up and Pullout Mechanism of Suction Caisson in a Soft Clay Seabed.Marine Georesources \& Geotechnology,32(2):135-154,2014.

21. Watson, P.G., Suemasa, N. and Randolph, M.F.."Evaluating undrained shear strength using the vane shear apparatus." Proc. 10th Int. Conf. On Offshore and Polar Engng,ISOPE 99, Seattle, 2, 485-493, 2000

22. Randolph, M. F.,House,A.R.. "Analysis of suction caisson capacity in clay" Proc., Annual Offshore Technology Conf., Offshore Technology Conference, Houston, OTC 14236, 2002.

23. Skempton, A. W.. The bearing capacity of clays. Proc. Building Research Cong. London, 1, 180-189, 1951.

24. Byrne, B.W., Cassidy, M.J.. Investigating the response of offshore foundations in soft clay soils. In: Proceedings of the 21st International Conference on Offshore Mechanics and Arctic Engineering OMAE'02, Oslo, paper OMAE2002- 28057, 2002. 
25. Hung, L. C. Kim, S. R. Evaluation of vertical and horizontal bearing capacities of bucket foundations in clay. Ocean Engineering, 52, pp.75-82, 2012.

26. Gourvenec, S.Effect of embedment on the undrained capacity of shallow foundations under general loading Géotechnique,58(3):177-185, 2008.

27. Det Norske Veritas. Geotechnical Design and Installation of Suction Anchors in Clay. DNV Recommended Practice RP-E303, 2005.

\title{
CONTACT WITH THE AUTHORS
}

\author{
Jiaqing $\mathrm{Du}^{\mathrm{a}}$ \\ Shouji $\mathrm{Du}^{\mathrm{a}}$ \\ Shuilong Shen ${ }^{\mathrm{a}}$ \\ Zhenyu Yina ${ }^{\mathrm{b}}$ \\ ${ }^{a}$ Department of Civil Engineering and State Key \\ Laboratory of Ocean Engineering \\ Shanghai Jiao Tong University \\ Shanghai 200240 \\ CHINA \\ email: dusj@sjtu.edu.cn \\ ${ }^{b}$ LUNAM University \\ Ecole Centrale de Nantes \\ GeM UMR CNRS, 6183 \\ Nantes \\ FRANCE
}

